\title{
Study on the Equilibrium Discriminant Model of Urban Agglomeration Transport Supply and Demand Structure
}

\author{
Z. Y. Liu $(D)$, C. B. Li $(\mathbb{D}$, and M. Y. Jian \\ Transportation Institute, Inner Mongolia University, Hohhot 010021, China \\ Correspondence should be addressed to C. B. Li; bingbingnihao2008@126.com
}

Received 4 May 2018; Revised 7 August 2018; Accepted 30 August 2018; Published 25 September 2018

Academic Editor: Jaeyoung Lee

Copyright (c) 2018 Z. Y. Liu et al. This is an open access article distributed under the Creative Commons Attribution License, which permits unrestricted use, distribution, and reproduction in any medium, provided the original work is properly cited.

\begin{abstract}
In order to study the adaptability of urban agglomeration transport supply and demand structure, and to provide the basis for decision-makers when optimizing the structure of transport supply and demand in urban agglomeration, this paper proposed and verified a structure equilibrium theory on the basis of entropy theory. Firstly, based on the analysis of the influencing factors, an urban agglomeration transport demand structure model was established using entropy theory. Secondly, according to the actual passenger and freight turnover of urban agglomeration, a transport supply structure model was proposed with entropy theory. Then, by comparing the two entropy models, the equilibrium state of an urban agglomeration transport structure was analyzed. Finally, HuBaoOr urban agglomeration was taken as an example to verify the science and effectiveness of this discriminant model. The research in this paper lays a theoretical foundation for the achievement of urban agglomeration transport equilibrium structure and for realizing the best economic benefits and social benefits.
\end{abstract}

\section{Introduction}

With the development of information technology and city economy, the phenomenon of urban agglomeration increases, and the urban agglomeration will be an important trend of the urban development in the future. During the development process of urban agglomeration, transportation structure including transport supply structure and transport demand structure plays an important role as a base installation. Therefore, transportation structure should reach a state of harmony with the development of urban agglomeration. In an advanced and modern transport system of urban agglomeration, a relatively stable transport supply structure and transport demand structure formed under certain economic and demographic conditions should match each other. This state will be a dynamic equilibrium state and the utilization of any transport supply resource achieves the best outcome. However, due to the lack of comprehensive planning and effective coordination mechanism in our country, there are often disequilibrium phenomena in the transport supply structure and demand structure, which will hinder the economy development of urban agglomeration in turn.
Lots of literatures $[1,2]$ have focused on the equilibrium structure of transport supply and demand and proposed evaluating methods about supply and demand balance state of urban traffic. Due to serious traffic problem, the RACV (Royal Automobile Club of Victoria, Ltd) management strategy [3] was put forward to balance the traffic supply and demand. Yuan [4] studied the equilibrium problems of transport demand structure and supply structure by considering the relationship between transportation and social economic development. Taking adaptation of the regional freight supply and demand structure as the research object, Tang et al. [5] analyzed the corresponding influencing factors, built an evaluation model for the adaptation, and put forward the adaptability evaluation standard using the information entropy theory. $\mathrm{Lu} \mathrm{[6]} \mathrm{discussed} \mathrm{the} \mathrm{main} \mathrm{influencing} \mathrm{factors} \mathrm{and} \mathrm{put}$ forward the research content of transport supply strategy and demand management measures. Wu et al. [7] quantitatively analyzed the causal relationship between China's industrial structure and transportation structure through the test on industrial structure and transportation structure entropy based on the qualitative analysis of interaction mechanism between transport supply and demand. Wei Jun et al. [8] 
and Daniel Hörcher [9] proposed the equilibrium conditions of transport demand and supply using system dynamics principle and considered the temporal, spatial, and directional demand imbalances. The supply and demand relationship with economy and transportation structure equilibrium problem considered by the equilibrium concept was also studied by Wu wenzheng [10] and Carey.G.W [11]. Ge Yu et al. [12] formed transport investment structure and transport demand coordination model of Beijing by comparing the transport investment structure and transport development characteristics between international metropolis and the city of Beijing. Pei Wu [13] studied the road network characteristics of urban agglomeration with some quantitative methods, such as the traffic assignment algorithm based on the path and the design algorithm of the integrated hybrid road network. Liu Zhijie [14] studied the hierarchy of groups and impact of urban agglomeration transportation systems from a macro point of view. Gao Yan [15] discussed the evaluation methodology for the intercity transportation system development of urban agglomeration, mainly on rail transit, based on some basic characteristics and associated theories of urban agglomeration.

In conclusion, there are many researches about transport supply and demand structure of a single city road network. The key problem they want to solve is traffic congestion and the proposed measures always include limiting the travel of cars on the demand side and increasing the capacity of the road network on the supply side within the city. There is very little research about an urban agglomeration, and if there is one, it often focuses on the macro development characteristic of urban agglomeration transport system and specific plans still within one administrative region lacking in-depth analysis of the internal relationship between transport supply and demand structure of urban agglomeration. The key problem to be solved in an urban agglomeration transport structure is to adjust supply to boost demand and promote the economic development of urban agglomeration through the coordination of the supply structure and demand structure subjected to the existing supply resources. Of course, the supply resources will change with the economic development of an urban agglomeration. So, we try to realize a dynamic equilibrium state through the adjustment and coordination measures which include the proportion of modes of transport and the spatial hierarchical structure of transport system between cities.

Since the formation and function of urban agglomeration cannot be separated from the improvement of the service capacity of transportation system, an equilibrium transport supply and demand structure has become an inevitable requirement for the development of urban agglomeration. Therefore, the equilibrium problem of transport supply and demand structure is one of the urgent problems to be solved at home and abroad.

Based on this, by studying the relationship between the transport supply structure and transport demand structure of urban agglomeration, the discriminant model of transport supply-demand equilibrium of urban agglomeration is built in this paper which can quantitatively evaluate the development degree and the equilibrium state of urban agglomeration transport supply-demand structure. This method can provide a theoretical foundation for realizing reasonable configuration and equilibrium structure of urban agglomeration transport resource.

\section{Description of the Equilibrium Structure of Transport Supply and Demand}

Multicenter group is the main spatial form of urban agglomeration. In this form, an urban agglomeration transport supply structure and demand structure include internal transport supply and demand of a city inside urban agglomeration, intercity transport supply, and demand between two center cities within urban agglomeration and intercity transport supply and demand between a center city and another noncenter city within urban agglomeration. With respect to an urban agglomeration, the passenger and freight transport not only consider the traffic hub and traffic system in a city, but also consider the optimum transport path of the whole urban agglomeration in accordance with the minimum cost and the maximum return principle. Therefore, the internal and external transport supply and demand of an urban agglomeration should be unified planning including center city and non-center city.

In the rapid development of urban agglomeration in our country, there are many problems in construction of transportation system, which are mainly manifested in two ways, the coexistence of poor supply and unused portion of transport capacity and the coexistence of backward transport infrastructure and low utilization rate of part advanced infrastructures [16]. The transport supply-demand equilibrium structure of urban agglomeration researched in this paper is a relatively dynamic equilibrium structure at a certain time rather than an absolute equilibrium state with completely equal total supply and demand amount. It is common knowledge that the change of transportation supply always lags behind the change of transportation demand, so the relatively equilibrium state researched in this paper is a kind of dynamic equilibrium structure under the state of being short of supply. With the development of social economy of urban agglomeration, a new transport demand structure in the short term can be formed, while the transport supply structure cannot adapt to changed transport demand in the short term and this will result in a short term transport supply-demand disequilibrium structure of urban agglomeration. By this time, transportation governors and producers should adjust the transport supply structure to meet the changed demand structure. Before reaching the absolute equilibrium state by changing transport supply total amount, the transport supply and demand structure should be adjusted to achieve a relatively equilibrium state. The transition of supply-demand structure state is shown in Figure 1.

\section{Analysis of the Factors Affecting the Equilibrium of Traffic Demand-Supply Structure of Urban Agglomeration}

(1) Industrial Structure Adjustment of Urban Agglomeration. The change of industrial structure is the root of the change 


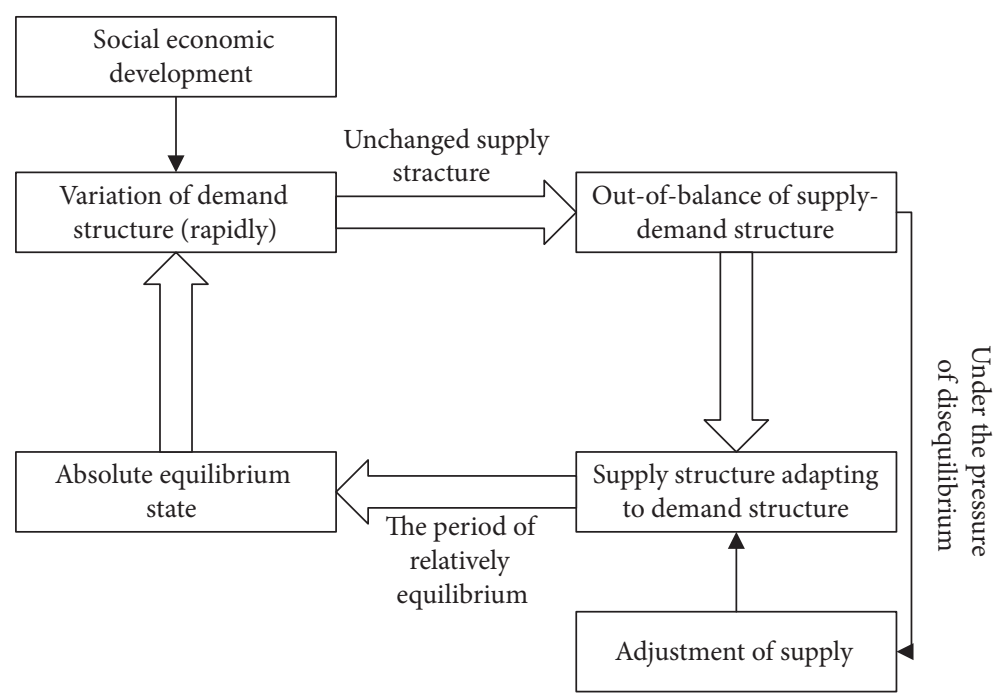

FIgURE 1: The transition of supply and demand structure state.

of the transport structure. Due to the adjustment in the ratio of various industries, type, flow, and direction of cargoes are all going to be different, and then the transport demand of urban agglomeration will change affecting the adaptability of transport supply and demand structure.

(2) Resident Consumption Structure of Urban Agglomeration. Income and consumption level of residents determine their preference to various modes of transport, thus forming a different passenger demand structure at different economic development level and stage. With the development of city economy, residents' consumption level continues to improve, and then the transport demand will also increase and show a trend of diversity, which will cause the change of urban agglomeration transport demand structure.

(3) Economic Relationship between Cities in Urban Agglomeration. The development of one city can well impact others' in urban agglomeration, while the economic relationship between different cities is different. The different degree of economic relationship between different cities leads to the different transport demand structure in an urban agglomeration. Here, we take the recessive economic gravity model [13] to represent the economic relationship between cities.

(4) Population Quantity and Size of Urban Agglomeration. The change of supply-demand equilibrium structure of passenger transport is closely related to population quantity and trip frequency. Increase of urban agglomeration population will cause the increase of city passenger transport demand, which will have an impact on the transport demand structure. Urban agglomeration population increases with the expansion of urban agglomeration scale, so the size of urban agglomeration can be reflected by the population in turn.

(5) Geographical Environment of Urban Agglomeration. Different urban agglomeration has different geographical environment, including the inland and coastal terrain differences, topography differences, and border distance differences. The different geographical environments need different transport modes, thus forming a unique transport demand structure of urban agglomeration.

(6) Other Influencing Factors. The energy structure, economic development strategy, transportation technology, and economic policy of urban agglomeration will also affect the transport demand structure. But, these factors are relatively stable in a certain period of time, almost no change, and their influence on urban agglomeration transport demand structure is also relatively small. So these factors will be temporarily ignored in the following construction of the transport demand structure function.

\section{Building Equilibrium Discriminant Model of Urban Agglomeration Transport Supply-Demand Structure}

4.1. Basic Idea of Modeling. We have to determine the research area before description of equilibrium problems of urban agglomeration transport supply and demand structure. The research area consists of two parts: all center cities and other closely neighboring cities (called non-center cities) involved in the urban agglomeration. $S=\left\{s_{q} \mid 1 \leq q \leq n\right\}$ denote the set of cities in the research area. $S^{\prime}=\left\{s_{p} \mid 1 \leq\right.$ $p \leq m\}$ denote the set of center cities of selected urban agglomeration. It is obvious that $S^{\prime} \subset S$.

(1) If $i=j$ and $1 \leq i \leq m, 1 \leq j \leq m$, then $s_{i}, s_{j}$ denote the same city in the urban agglomeration. At this point, the research object becomes a transport supply and demand relation of a single city in the urban agglomeration.

(2) If $i \neq j$ and $1 \leq i \leq j \leq m$, the research object is intercity relationship between center cities in the urban agglomeration. 


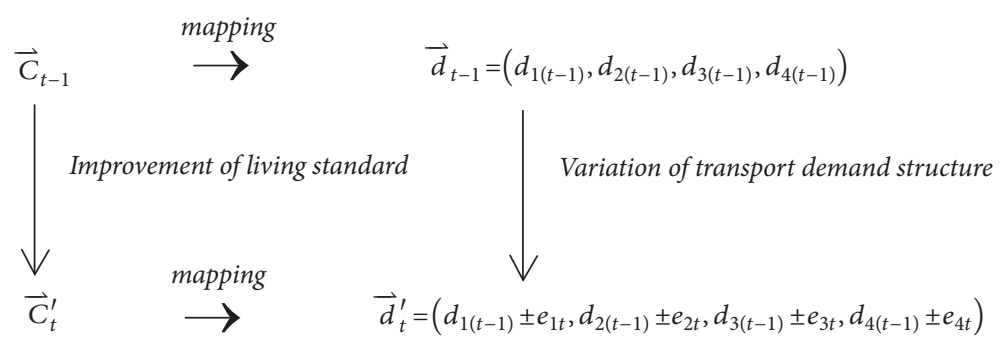

FIGURE 2: Mapping process from residents' consumption structure to transport demand.

(3) For any $s_{i} \in S$ and $s_{i} \notin S^{\prime}, s_{j} \in S^{\prime}$, the research object will be intercity relationship between a center city and a noncenter city in the urban agglomeration.

In order to describe equilibrium relationship between transport supply-demand structures of an urban agglomeration, firstly we need to establish urban agglomeration demand model and urban agglomeration supply model, respectively. Then we can determine the equilibrium state by comparing the above two models.

In this paper, the entropy theory is used to model urban agglomeration transport demand structure to quantitatively describe the spatial hierarchical transport demand structure between cities in an urban agglomeration based on the factors influencing the transport demand structure. As mentioned above, the relatively equilibrium state researched in this paper is a kind of dynamic equilibrium structure under the state of being short of supply, which means the total demand is greater than the total supply. So, in the modeling process of supply structure, actual transport volume of each traffic mode between cities of different hierarchical structures in an urban agglomeration is treated as transport supply, and the supply entropy is calculated. The discriminant model of transport supply-demand equilibrium state of urban agglomeration is built with the transport demand entropy and transport supply entropy which can reflect the equilibrium degree of the supply-demand structure intuitively.

4.2. Modeling Urban Agglomeration Transport Demand Structure. In the model of urban agglomeration transport demand structure, factors affecting demand are function variables. The function expression is as follows:

$$
D(\vec{d})=f(\vec{I}, F, \vec{C}, N, L, \varepsilon),
$$

where $\vec{d}$ is transport demand vector, $\vec{I}$ is industrial structure vector, $F$ is economic gravity between cities, $\vec{C}$ is consumption structure vector, $N$ is population size, $L$ is geographical environment, and $\varepsilon$ denotes other influencing factors.

City transport demand structure vector and its influencing factors belong to different dimensions, and influencing factors include number attribute and nonnumber attribute which makes it difficult to quantify all the factors unified. So, entropy theory is introduced in this paper to quantitatively describe the relationship between the factors and urban agglomeration supply-demand structure.

(1) Industrial Structure Entropy of Urban Agglomeration. According to the definition of the structure entropy, we can calculate the corresponding industrial structure entropy in different periods and use the industrial structure entropy to reflect the changes of the industry in different economic development stages of urban agglomeration.

If $H_{I}(t)$ denotes the industrial structure entropy at period $t$, then

$$
H_{I}(t)=-\sum_{j=1}^{3} P_{\mathrm{jt}} \ln P_{j t},
$$

where $P_{j t}$ is percentage of industry $j$ at period $t$, and

$$
\begin{aligned}
& P_{\mathrm{jt}}=\frac{\mathrm{I}_{\mathrm{jt}}}{\sum_{\mathrm{j}=1}^{3} \mathrm{I}_{\mathrm{jt}}} \\
& I_{j t}=\sum_{i=1}^{\mathrm{n}} I_{i j t} .
\end{aligned}
$$

In this equation, $I_{j t}$ is production value of industry $j$ at period $t$ and $I_{i j t}$ is production value of industry $j$ at period $t$ of city $s_{i} . j$ denotes the industry type, such as primary industry, secondary industry, and tertiary industry.

(2) Residents' Consumption Structure Entropy of Urban Agglomeration. Because the residents' consumption structure vector is hard to quantify description, the residents' consumption structure is mapped to transport demand of four kinds of transport modes. Then the change of residents' consumption structure corresponds to the change of transport demand. The mapping process can be described through Figure 2.

In Figure 2,

$$
\vec{C}(t-1)=\sum_{i=1}^{\mathrm{n}} \vec{C}_{i}(t-1)
$$




$$
\begin{gathered}
d_{j}(t-1)=\sum_{i=1}^{n} d_{i j}(t-1) \\
e_{j t}=\sum_{i=1}^{n} e_{i j t} .
\end{gathered}
$$

If $H_{c}(t)$ denotes the consumption structure entropy at period $t$, then

$$
\begin{gathered}
H_{c}(t)=-\sum_{j=1}^{4} Q_{j(t)} \ln Q_{j}(t) \\
Q_{j(t)}=\frac{\left(d_{j(t-1)} \pm e_{j t}\right)}{\sum_{j=1}^{4}\left(d_{j(t-1)} \pm e_{j t}\right)},
\end{gathered}
$$

where

1

$\vec{C}_{t-1}$ is residents' consumption structure vector at time $t-$

$\vec{C}_{t}^{\prime}$ is residents' consumption structure vector at time $t$

$\vec{d}_{t-1}$ is transport demand vector corresponding to residents' consumption structure at time $t-1$

$\vec{d}_{t}^{\prime}$ is transport demand vector corresponding to residents' consumption structure at time $t$

$d_{j(t-1)}$ is transport volume of mode $j$ (including roads, railways, aviation, and water transport mode) of urban agglomeration corresponding to residents' consumption structure at time $t-1$

$d_{i j(t-1)}$ is transport volume of mode $j$ of city $s_{i}$ corresponding to residents' consumption structure at time $t-1$

$e_{j t}$ is transport demand variation of mode $j$ corresponding to change of residents' consumption from time $t-1$ to time $t$

$e_{i j t}$ is transport demand variation of mode $j$ of city $s_{i}$ corresponding to change of residents' consumption from time $t-1$ to time $t$

(3) Entropy about Economic Relationship between Cities of Urban Agglomeration. Firstly, recessive economic gravity model is used to measure the economic relationship between cities. Recessive economic gravity model can clearly express the development ability of cities and more accurately calculate the economic attractiveness between cities. The calculation formula of the model is as follows:

$$
F_{i j}(t)=k_{i j} \bullet \frac{\left(P_{i}^{1}+P_{i}^{2}\right)_{V_{i}} *\left(P_{j}^{1}+P_{j}^{2}\right)_{V_{j}}}{r_{i j}^{2}} .
$$

In this paper we just consider the relationship between cities at time $t$ and there is no need to consider the potential economic demand of cities. So the above formula can be simplified to formula (11).

$$
F_{i j}(\mathrm{t})^{\prime}=k_{i j} \cdot \frac{P_{i V_{i}}^{1} * P_{j V_{j}}^{1}}{r_{i j}^{2}}
$$

where

$F_{i j}$ is index of recessive economic gravity

$P_{i}^{1}, P_{j}^{1}$ are economic index of cities $s_{i}$ and $s_{j}$ (GDP, billion yuan)

$P_{i}^{2}, P_{j}^{2}$ are potential economic demand index of cities $s_{i}$ and $s_{j}$ (billion yuan)

$V_{i}, V_{j}$ are population index of cities $s_{i}$ and $s_{j}$ (billion people)

$r_{i j}$ is the minimum distance between cities $s_{i}$ and $s_{j}$ (hours)

$k_{i j}$ is adjustment coefficient of recessive economic gravity, $k_{i j}=1$

If $H_{F}(t)$ denotes entropy of economic relationship between cities at period $t$, then

$$
\begin{aligned}
H_{F}(t) & =-\sum_{i=1}^{\mathrm{n}} \sum_{j=1}^{\mathrm{n}} R_{\mathrm{ij}} \ln R_{i j} \\
R_{\mathrm{ij}} & =\frac{F_{i j}(t)^{\prime}}{\sum_{i=1}^{\mathrm{n}} \sum_{j=1}^{n} F_{i j}(t)^{\prime}} .
\end{aligned}
$$

(4) Entropy of Urban Agglomeration Population Size. The urban agglomeration population size is mapped to transport demand of four kinds of transport modes as residents' consumption structure. The mapping process can be described through Figure 3.

In Figure 3,

$$
\begin{aligned}
\mathrm{N}(\mathrm{t}-1) & =\sum_{i=1}^{n} N_{i}(t-1) \\
\mathrm{d}_{\mathrm{j}}(t-1) & =\sum_{\mathrm{i}=1}^{\mathrm{n}} d_{i j(t-1)} \\
g_{j t} & =\sum_{i=1}^{n} g_{i j t} .
\end{aligned}
$$

If $H_{N}(t)$ denotes entropy of urban agglomeration population size at period $t$, then

$$
\begin{aligned}
H_{N}(t) & =-\sum_{j=1}^{4} S_{j t} \ln S_{j t} \\
S_{j \mathrm{t}} & =\frac{\left(d_{j(t-1)}+g_{j t}\right)}{\sum_{j=1}^{4}\left(d_{j(t-1)}+g_{j t}\right)}
\end{aligned}
$$

and

$N_{t-1}$ is population size of urban agglomeration at time $t-$ 1

$N_{t}^{\prime}$ is population size of urban agglomeration at time $t$ $\vec{d}_{t-1}$ is transport demand vector corresponding to population size at time $t-1$

$\vec{d}_{t}^{\prime}$ is transport demand vector corresponding to population size at time $t$

$d_{j}(t-1)$ is transport volume of mode $j$ (including roads, railways, aviation, and water transport mode) of urban agglomeration corresponding to population size at time $t-1$ 


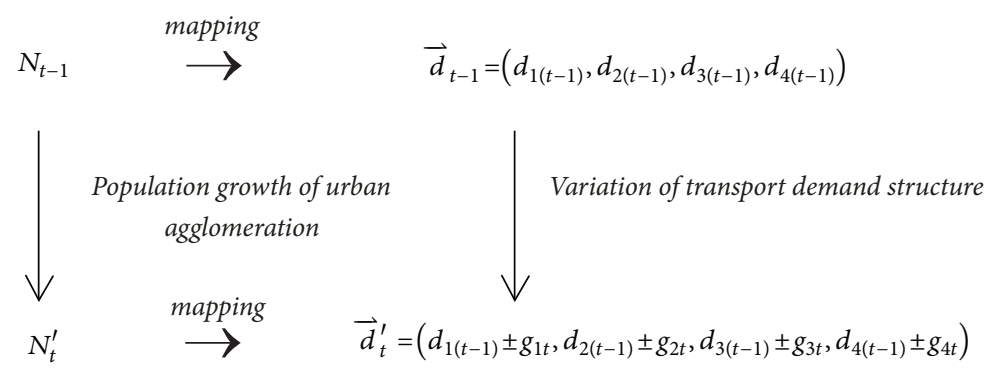

FIGURE 3: Mapping process from population size to transport demand.

$d_{i j}(t-1)$ is transport volume of mode $j$ of city $s_{i}$ corresponding to population size at time $t-1$

$g_{j t}$ is transport demand variation of mode $j$ corresponding to change of population size from time $t-1$ to time $t$

$g_{i j t}$ is transport demand variation of mode $j$ of city $s_{i}$ corresponding to change of population size from time $t-1$ to time $t$

(5) Entropy of Geographical Environment of Urban Agglomeration. The geographical environment of urban agglomeration is a fixed factor which does not change with time. Therefore, the vector of the transport demand structure corresponding to the geographical location of the urban agglomeration is fixed, as formula (19).

$$
\vec{d}_{L}=\left(d_{L 1}, d_{L 2}, d_{L 3}, d_{L 4}\right)
$$

If $H_{L}$ denotes entropy of geographical environment, then

$$
\begin{aligned}
H_{L} & =-\sum_{i=1}^{4} L_{i} \ln L_{i} \\
L_{i} & =\frac{d_{L i}}{\sum_{i=1}^{4} d_{L i}}
\end{aligned}
$$

and $d_{L i}$ is transport supply quantity of mode $j$ corresponding to geographical environment of urban agglomeration.

According to the above entropy of the influencing factors the ultimate transport demand structure function is drawn by the method of undetermined coefficients. The transport demand structure entropy model is as formula (22).

$$
\begin{aligned}
H_{D}(t, d)= & a H_{I}(\mathrm{t})+b H_{C}(t)+c H_{F}(t)+d H_{N}(t) \\
& +e H_{L}+\varepsilon(t) .
\end{aligned}
$$

$a, b, c, d, e$ are undetermined coefficients, which represent the weights of the five factors in part 2 , and the sum of the weights is 1 . The weight needs to be determined according to the specific development stage of urban agglomeration. $\varepsilon(t)$ is residual variable.

4.3. Modeling Urban Agglomeration Transport Supply Structure. The actual volume of the four transport modes is treated as urban agglomeration transport supply volume. If $x_{1}, x_{2}, x_{3}$ denote the weights of three types of supply-demand structure, respectively, which are a transport supply and demand relation of a single city in the urban agglomeration, intercity relationship between center cities, and intercity relationship between a center city and a non-center city in the urban agglomeration, then transport supply structure vector at time $t$ is expressed as formula (23) and (24).

$$
\begin{aligned}
\vec{G}_{t}= & \left(g_{1 t}, g_{2 t}, g_{3 t}, g_{4 t}\right) \\
g_{i t}= & \sum_{j=1}^{m} g_{i j t} \\
= & x_{1} \sum_{\mathrm{j}=\mathrm{k}=1}^{m} g_{i j t(j, k)}+x_{2} \sum_{\mathrm{j}=1}^{m} \sum_{k=i+1}^{m} g_{i j t(j, k)} \\
& +x_{3} \sum_{\mathrm{j}=1}^{m} \sum_{k=m+1}^{n} g_{i j t(j, k)},
\end{aligned}
$$

where $g_{i t}$ is the transport volume of mode $i$ in urban agglomeration and $g_{i j t}(j, k)$ is the transport volume of mode $i$ between the city $s_{j}$ and city $s_{k}$ at time $t$.

Entropy of transport supply structure at time $t$ can be calculated through formula (25).

$$
H_{G}(t, g)=-\sum_{i=1}^{4} T_{i t} \ln T_{i t} .
$$

And

$$
T_{\text {it }}=\frac{\mathrm{g}_{\mathrm{it}}}{\sum_{\mathrm{i}=1}^{4} \mathrm{~g}_{\mathrm{it}}} .
$$

4.4. Equilibrium Discriminating of Urban Agglomeration Transport Supply and Demand Structure. To describe the disequilibrium degree of urban agglomeration transport supply-demand structure, transport supply structure entropy and transport demand structure entropy are compared in the model. If the ratio of supply entropy and demand entropy is closer to 1 , the two entropies are closer, and the transport supply and demand structure is more balanced. The disequilibrium degree at time $t$ is calculated as follows:

$$
G(t)=\left|1-\frac{H_{G}(t, g)}{H_{D}(t, g)}\right| .
$$

If $H_{D}(t, d)=H_{G}(t, g), G(t)$ will be zero which indicates an absolute equilibrium of the supply-demand structure.

According to the definition of the concept of equilibrium and the division of transport supply and demand structure equilibrium level given by [4], this paper divides the equilibrium degree of urban transport demand and supply structure into categories as shown in Table 1. 
TABLE 1: The division of transport supply and demand structure equilibrium level.

\begin{tabular}{lcc}
\hline types & equilibrium level & $G(t)$ \\
\hline \multirow{2}{*}{ equilibrium structure } & high quality equilibrium & $0<G(t) \leq 0.1$ \\
& marginal equilibrium & $0.1<G(t) \leq 0.2$ \\
interim stage & just equilibrium & $0.2<G(t) \leq 0.3$ \\
& near disequilibrium & $0.3<G(t) \leq 0.4$ \\
disequilibrium structure & mild disequilibrium & $0.4<G(t) \leq 0.6$ \\
& severe disequilibrium & $0.6<G(t) \leq 1$ \\
\hline
\end{tabular}

\section{Case Analysis}

In order to confirm the above method, HuBaoOr urban agglomeration is taken as an example to analyze the equilibrium state of transport supply and demand structure.

HuBaoOr urban agglomeration includes three center cities, Hohhot, Baotou, and Ordos, and three non-center cities, Ulanqab, Byannur, and Wuhai.

In the calculation process, some data are difficult to access, so only two factors, the industrial structure adjustment of urban agglomeration and city economic relationship between cities, are used in modeling transport demand structure and the two factors' weights are equal, $a=c=0.5$.

(1) Entropy of Urban Agglomeration Transport Demand Structure. Firstly, industrial structure entropy of urban agglomeration will be calculated using formula (2). Production value of three main industries in HuBaoOr urban agglomeration is shown in Table 2.

$$
\begin{gathered}
I_{1 t}=\sum_{i=1}^{6} I_{i 1 t}=629.01 \text { (billion) } \\
I_{2 t}=\sum_{i=1}^{6} I_{i 2 t}=6359.89 \text { (billion) } \\
I_{3 \mathrm{t}}=\sum_{i=1}^{6} I_{i 3 t}=6520.68 \text { (billion) } \\
P_{1 t}=\frac{I_{1 t}}{\sum_{i=1}^{3} I_{i t}}=0.046560293 \\
P_{2 t}=\frac{I_{2 t}}{\sum_{i=1}^{3} I_{i t}}=0.470768891 \\
P_{3 t}=\frac{I_{3 t}}{\sum_{i=1}^{3} I_{i t}}=0.482670816 .
\end{gathered}
$$

Then industrial structure entropy $H_{I}$ is 0.8495 .

$$
H_{I}=-\sum_{\mathrm{j}=1}^{3} P_{\mathrm{jt}} \ln \mathrm{P}_{\mathrm{jt}}=0.8495 \text {. }
$$

Secondly, entropy about economic relationship between cities of urban agglomeration will be calculated using formula (12). Center cities are considered in the model to simplify the
TABLE 2: Production value of three main industries in HuBaoOr urban agglomeration.

\begin{tabular}{lccc}
\hline city & $\begin{array}{c}\text { primary } \\
\text { industry (billion } \\
\text { yuan) }\end{array}$ & $\begin{array}{c}\text { secondary industry } \\
\text { (billion yuan) }\end{array}$ & $\begin{array}{c}\text { Tertiary industry } \\
\text { (billion yuan) }\end{array}$ \\
\hline Hohhot & 126.23 & 867.08 & 2097.21 \\
\hline Baotou & 101.05 & 1830.64 & 1850.24 \\
\hline Ordos & 98.96 & 2400.01 & 1727.15 \\
\hline Ulanqab & 132.39 & 443.84 & 337.53 \\
\hline Byannur & 165.64 & 450.55 & 271.24 \\
\hline Wuhai & 4.74 & 367.77 & 237.31 \\
\hline
\end{tabular}

TABLE 3: GDP of each city in 2015(billion yuan).

\begin{tabular}{lc}
\hline Hohhot & 3090.52 \\
\hline Baotou & 3781.93 \\
\hline Ordos & 4426.13 \\
\hline Ulanqab & 913.77 \\
\hline Byannur & 887.43 \\
\hline Wuhai & 609.82 \\
\hline
\end{tabular}

process. Index of GDP, population, and distance needed in the calculation process are shown in Tables 3,4 , and 5 .

Recessive economic gravity between center cities is calculated by formula (11).

$$
\text { Hohhot-Baotou : } F_{1}^{\prime}=k \cdot \frac{P_{H u}^{1} V_{H u} * P_{B a o}^{1} V_{B a o}}{r_{H u-B a o}^{2}}
$$$$
=335.85
$$

$$
\begin{aligned}
& \text { Hohhot-Ordos : } F_{2}^{\prime}=k \cdot \frac{P_{\mathrm{Hu}}^{1} V_{\mathrm{Hu}} * P_{\mathrm{Or}}^{1} V_{\mathrm{O}}}{r_{\mathrm{Hu}-\mathrm{Or}}^{2}} \\
& \quad=158.33
\end{aligned}
$$

$$
\begin{aligned}
& \text { Baotou-Ordos : } F_{3}^{\prime}=k \cdot \frac{P_{B a o}^{1} V_{B a o} * P_{\mathrm{Or}}^{1} V_{\mathrm{O} r}}{r_{B a 0-\mathrm{O} r}^{2}} \\
& \quad=175.40
\end{aligned}
$$

$$
\begin{aligned}
& R_{1 t}=\frac{F_{1}^{\prime}}{\sum_{j=1}^{3} F_{j}^{\prime}}=0.50 \\
& R_{2 t}=\frac{F_{2}^{\prime}}{\sum_{j=1}^{3} F_{j}^{\prime}}=0.24 \\
& R_{3 t}=\frac{F_{3}^{\prime}}{\sum_{j=1}^{3} F_{j}^{\prime}}=0.26 .
\end{aligned}
$$

Then entropy about economic relationship between cities of urban agglomeration $H_{F}$ is 1.0393 .

$$
H_{F}=-\sum_{j=1}^{3} R_{j t} \ln R_{j t}=1.0393 .
$$


TABLE 4: Population of each city in 2015(billion people).

\begin{tabular}{ll}
\hline Hohhot & 0.0287 \\
\hline Baotou & 0.0265 \\
\hline Ordos & 0.0194 \\
\hline Ulanqab & 0.0214 \\
\hline Byannur & 0.0167 \\
\hline Wuhai & 0.0053 \\
\hline
\end{tabular}

TABLE 5: Distance between center cities (hour).

\begin{tabular}{lccc}
\hline & Transport mode & Distance $(\mathrm{km})$ & Time $(\mathrm{h})$ \\
\hline Hohhot-Baotou & High-speed rail & $165 \mathrm{~km}$ & $0.75 \mathrm{~h}$ \\
\hline Hohhot-Ordos & High-speed rail & $275 \mathrm{~km}$ & $1.05 \mathrm{~h}$ \\
\hline Baotou-Ordos & railway & $147 \mathrm{~km}$ & $1.03 \mathrm{~h}$ \\
\hline
\end{tabular}

Finally, the demand structure entropy $H_{D}(t)$ of $\mathrm{HuBaoOr}$ urban agglomeration is 0.9444 .

$$
H_{D}(t)=a H_{I}(t)+c H_{F}(t)=0.9444 .
$$

(2) Entropy of Transport Supply Structure. Transport supply of urban agglomeration includes a transport supply within a single city in the urban agglomeration, intercity supply between center cities in the urban agglomeration, and intercity supply between the center city and a non-center city, three types. Entropy of transport supply structure can be calculated with formula (25) and relevant data are showed in Table 6. The transport volume $g_{i t}$ of mode $i$ in urban agglomeration including two parts, passenger volume $g_{1 t}$ (passenger)and freight volume $g_{1 t}($ freight $)$.

$$
\begin{aligned}
& g_{1 t}(\text { passenger })=\sum_{j=1}^{3} g_{1 j t}(\text { passenger })=4963.35 \\
& g_{2 t}(\text { passenger })=\sum_{j=1}^{3} g_{2 j t}(\text { passenger })=4808.32 \\
& g_{3 t}(\text { passenger })=\sum_{j=1}^{3} g_{3 j t}(\text { passenger })=922.02 .
\end{aligned}
$$

According to China's statistic system, the conversion ratio of passenger turnover and freight turnover [17] is shown in Table 7.

$$
\begin{aligned}
& g_{1 t}=g_{1 t}(\text { passenger })+10 g_{1 t}(\text { freight })=18067.4 \\
& g_{2 t}=g_{2 t}(\text { passenger })+g_{2 t}(\text { freight })=1997.6 \\
& g_{3 t}=g_{3 t}(\text { passenger })+13.7 g_{3 t}(\text { freight })=1708.6 \\
& T_{1 t}=\frac{g_{1 t}}{\sum_{i=1}^{3} g_{i t}}=0.8297
\end{aligned}
$$

$$
\begin{aligned}
& T_{2 t}=\frac{g_{2 t}}{\sum_{i=1}^{3} g_{i t}}=0.0917 \\
& T_{3 t}=\frac{g_{3 t}}{\sum_{i=1}^{3} g_{i t}}=0.0784
\end{aligned}
$$

So, entropy of transport supply structure is 0.5736 .

Then, the equilibrium degree $G(t)$ at time $t$ can be acquired.

$$
G(t)=\left|1-\frac{H_{G}(t)}{H_{D}(t)}\right|=0.392 .
$$

Comparing the value $G(t)$ of HuBaoOr urban agglomeration with Table 1, the supply-demand structure is at "near disequilibrium state," which means there is a slightly mismatch between transport supply structure and transport demand structure. If the later development is not planned in advance, the disequilibrium will be significant which may result in a series of transport problems and waste of resources.

In the current state, we can adjust the transport supply of each mode in real time according to the transport demand structure changed with the development of urban agglomeration in case of disequilibrium. We try to realize a dynamic equilibrium state within a certain variation range through the adjustment and coordination measures which include the proportion of modes of transport and the spatial hierarchical structure of transport system between cities.

At present, the development of HuBaoOr urban agglomeration is in its initial stage and there is a slight mismatch between transport supply structure and transport demand structure. Later, in order to promote the economic development of urban agglomeration, it is necessary to study it in detail from the point of view of supply structure, and the focal points of construction in different regions should be different. Investment should be focused on the supply modes with higher demand in the region.

\section{Conclusion}

In this paper, we propose a transport supply-demand equilibrium problem of the urban agglomeration. Entropy theory is used to build transport demand structure entropy model, supply structure entropy model, and discriminant model of transport supply-demand equilibrium state to calculate the equilibrium degree of the supply-demand structure in an urban agglomeration. Following this, we have provided a case analysis of the proposed model using data of HuBaoOr urban agglomeration.

The influence factors of transport demand used to reflect the demand structure of urban agglomeration can better reflect the potential transport demand of the urban agglomeration, which can really reflect the influence of social and economic development of urban agglomeration on transport demand structure. The discriminant model of transport supply-demand equilibrium structure of urban agglomeration can be applied to most of the general urban agglomeration to judge the transport supply and demand structure equilibrium state and the appropriate measures 
TABLE 6: Turnover of passenger and freight of HuBaoOr urban agglomeration in 2015.

\begin{tabular}{|c|c|c|c|c|c|}
\hline & & turnover & roads & railways & aviation \\
\hline \multirow{6}{*}{ Baotou } & \multirow{2}{*}{ internal transport supply } & passenger & 13.35 & 1.53 & 0 \\
\hline & & freight & 49.35 & 9.56 & 0 \\
\hline & \multirow{2}{*}{ intercity transport supply with center cities } & passenger & 42.54 & 30.53 & 17.89 \\
\hline & & freight & 437.64 & 421.54 & 27.33 \\
\hline & \multirow{2}{*}{ intercity transport supply with non-center cities } & passenger & 4.62 & 58.25 & 21.45 \\
\hline & & freight & 62.25 & 84.63 & 19.34 \\
\hline \multirow{6}{*}{ Ordos } & \multirow{2}{*}{ internal transport supply } & passenger & 14.74 & 7.88 & 0 \\
\hline & & freight & 56.25 & 9.24 & 0 \\
\hline & \multirow{2}{*}{ intercity transport supply with center cities } & passenger & 57.38 & 68.32 & 32.15 \\
\hline & & freight & 478.25 & 474.21 & 20.08 \\
\hline & \multirow{2}{*}{ intercity transport supply with non-center cities } & passenger & 8.69 & 28.43 & 32.54 \\
\hline & & freight & 51.36 & 95.36 & 15.36 \\
\hline \multirow{6}{*}{ Hohhot } & \multirow{2}{*}{ internal transport supply } & passenger & 14.32 & 3.09 & 0 \\
\hline & & freight & 48.56 & 5.85 & 0 \\
\hline & \multirow{2}{*}{ intercity transport supply with center cities } & passenger & 72.38 & 43.25 & 37.68 \\
\hline & & freight & 552.79 & 517.83 & 18.26 \\
\hline & \multirow{2}{*}{ intercity transport supply with non-center cities } & passenger & 7.68 & 52.75 & 32.22 \\
\hline & & freight & 46.72 & 85.35 & 11.65 \\
\hline
\end{tabular}

TABLE 7: Conversion ratio of passenger turnover and freight turnover.

\begin{tabular}{lcccc}
\hline & $\begin{array}{c}\text { Roads } \\
\text { transport }\end{array}$ & $\begin{array}{c}\text { Railways } \\
\text { transport }\end{array}$ & $\begin{array}{c}\text { Aviation } \\
\text { transport }\end{array}$ & $\begin{array}{c}\text { Water } \\
\text { transport }\end{array}$ \\
\hline $\begin{array}{l}\text { Conversion ratio of } \\
\text { passenger turnover } \\
\text { and freight turnover }\end{array}$ & $10: 1$ & $1: 1$ & $13.7: 1$ & $2: 1$ \\
\hline
\end{tabular}

should be taken to adjust supply and demand of various transport modes promoting the achievement of dynamic equilibrium state.

There are also some research shortcomings in this paper. This paper does not consider the effect of transportation objects on supply-demand structure. Because the transport modes preferred by passenger transport and freight transport are different, and the proportion of urban passenger and freight demand is obviously different owing to different industry characteristics of cities, it will result in different demand structure. Therefore, the supply structure of different cities in the urban agglomeration should be treated differently in future research. There are also many undetermined parameters of the model in this paper. The values of some parameters are assumed by authors rather than derived by actual data. This paper only gives a kind of research thought and methods of analyzing problems. The appropriate setting of the parameters' value and the effect of parameter values on the results are worth investigating in the future and important real-word constraints to consider in future research.

\section{Data Availability}

The data used to support the findings of this study were freely available from the website of the Statistics
Bureau and Transport Bureau of Six Cities in the Inner Mongolia Autonomous Region and Inner Mongolia Statistical Yearbook 2015. The websites are as follows: http://tjj.huhhot.gov.cn/hhhttjj/index.asp, http://tjj.baotou .gov.cn/, http://www.ordoswsjs.gov.cn/, http://www.ordoswsjs.gov.cn/, http://www.wulanchabu.gov.cn/, http://tjj .bynr.gov.cn, http://tjj.wuhai.gov.cn/.

\section{Conflicts of Interest}

The authors declare that they have no conflicts of interest.

\section{Acknowledgments}

This work was financially supported by the Chinese National Natural Science Foundation (Project No. 51668048), the Inner Mongolia Natural Science Projects (Project No. 2014BS0501), and the Higher Educational Scientific Research Projects of Inner Mongolia Autonomous Region (Project No. NJZY17012).

\section{References}

[1] A. Zedgenizov and D. Burkov, "Methods for the Traffic Demand Assessment Based on the Quantitative Characteristics of Urban Areas Functioning," pp. 724-730.

[2] S. Chandra, M. Braughton, L. D. Galicia, A. Sanchez, M. Medina, and R. Aldrete, "A Multi-modal Transportation Score to Evaluate Infrastructure Supply-demand for Commuters," in Proceedings of the International Conference on Sustainable Design, Engineering and Construction, ICSDEC 2016, pp. 304311, USA, May 2016.

[3] T. J. Sanderson and I. B. Greenwood, "Demand management: a motoring organisation's perspective," in International Transport Conference, vol. 91, pp. 103-108, 1991. 
[4] Y. Jing, Study on the structure equilibrium of transportation supply and demand, Chang'an university, 2007.

[5] T. Jianqiao and W. Ciguang, "Adaptability between supply structure and demand structure of regional freight based on information entropy theory," Journal of highway and transportation research and development, vol. 30, no. 4, pp. 148-154, 2013.

[6] Lu. Huapu, "Strategies of supply of urban transport infrastructure and travel demand management," Urban transport of China, vol. 10, no. 3, pp. 1-6, 2012.

[7] Wu. Feng and Shi. Qizhou, "Entopy theory based study on relationship between transportation and industry systems," Journal of transportation systems engineering and information technology, vol. 6, no. 1, pp. 71-74, 2006.

[8] J. Wei and L. Li, "Model of dynamic relationship between traffic supply and demand," Chang'an Daxue Xuebao (Ziran Kexue Ban)/Journal of Chang'an University (Natural Science Edition), vol. 30, no. 6, pp. 86-98, 2010.

[9] D. Hörcher and D. J. Graham, "Demand imbalances and multiperiod public transport supply," Transportation Research Part B: Methodological, vol. 108, pp. 106-126, 2018.

[10] Wu. Wenzheng, Study on equilibrium theory of transportation supply and demand, Changan university, 2005.

[11] G. W. Accessibility, "Urbanization and Transportation: Towards an operational model transportation policy and urban rank: A model for the optimization of transport infrastructure. The transport Geography study group at the department of geography," university of salford, 2005.

[12] Yu. Ge, Z. Xiuyuan, and L. Wei, "Study on the adaptability of urban traffic infrastructural investment and traffic demand," Mathematics in practice and theory, vol. 12, no. 39, pp. 41-47, 2009.

[13] $\mathrm{P}$. Wu, The study on mixed highway network design for urban agglomeration, Changsha university of science and technology, 2008.

[14] Z. Liu, A study on transportation system planning for urban agglomerations, Changan university, 2011.

[15] Gao. Yan, Study on the evaluation for the inter-city transportation system development of urban agglomeration, Changan university, 2009.

[16] Li. Yanyan, Research on disequilibrium characteristics of urban traffic supply and demand, Jilin University, 2011.

[17] Dictionary of Communication Additions Series, Shanghai Science and Technology Literature Press, 2008. 


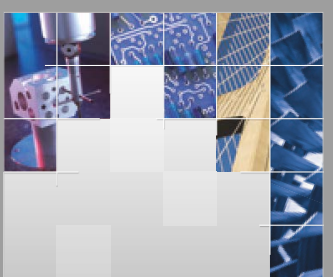

\section{Enfincering}
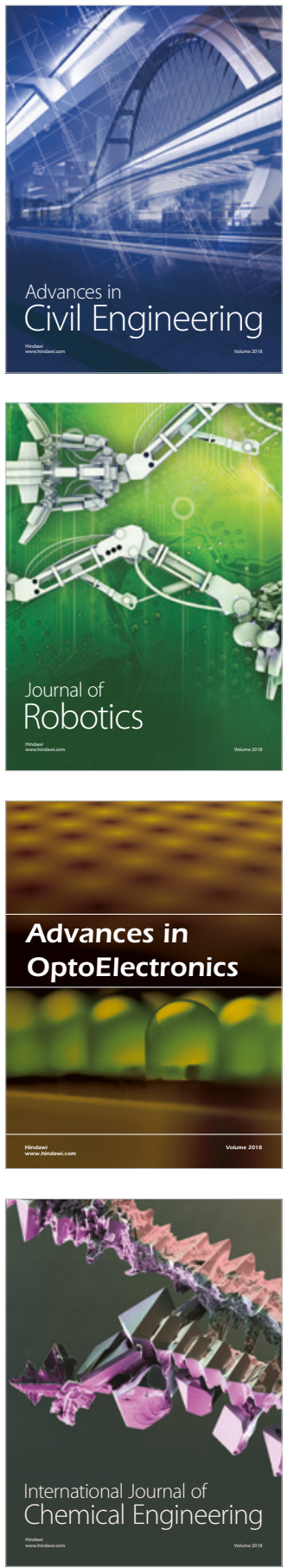

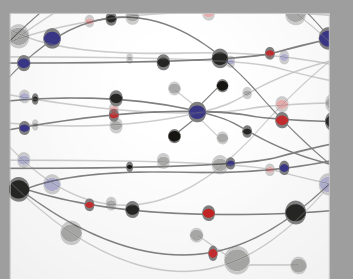

\section{Rotating \\ Machinery}

The Scientific World Journal

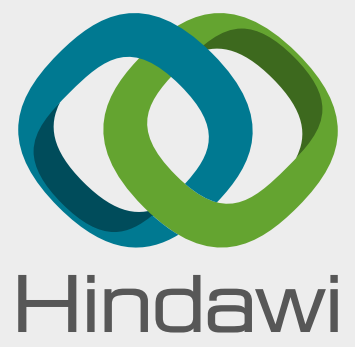

Submit your manuscripts at

www.hindawi.com
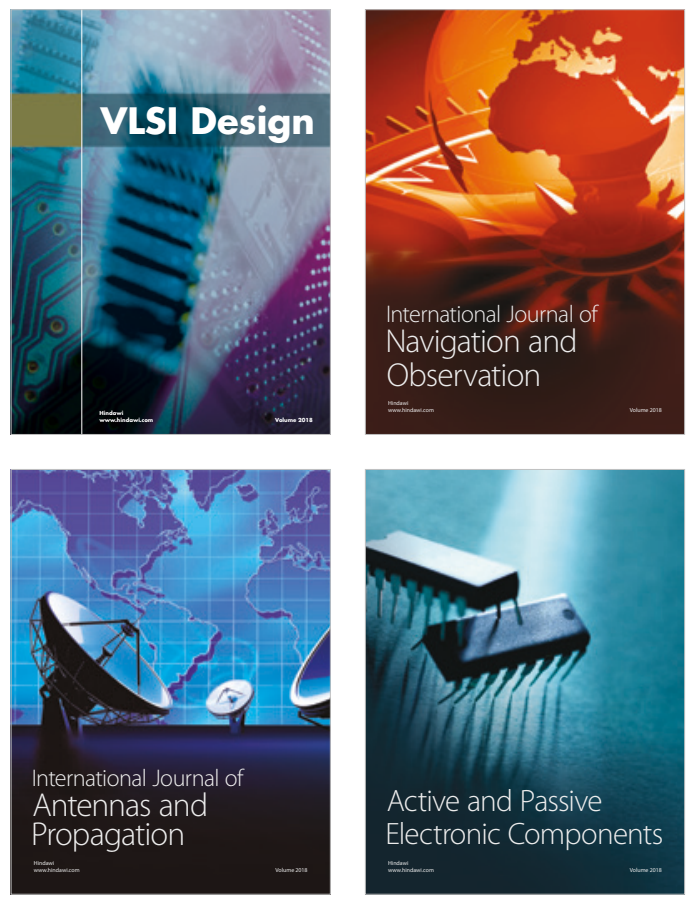
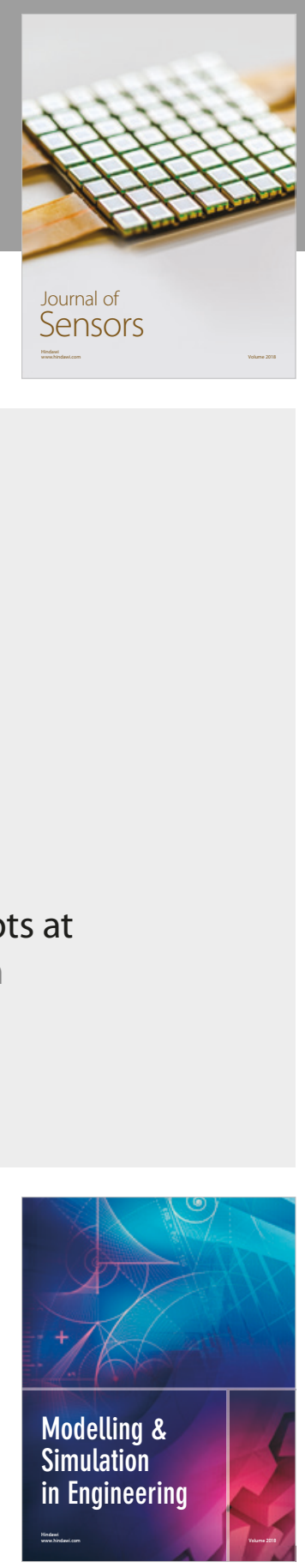

\section{Advances \\ Multimedia}
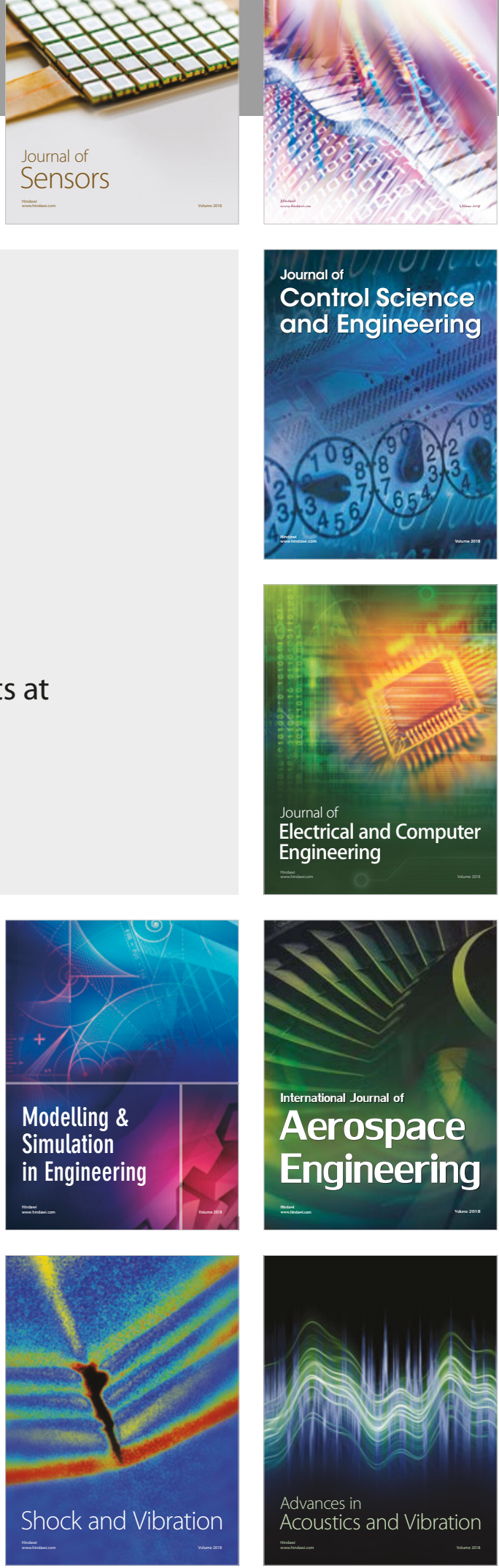